\title{
Fruit and vegetable products
}

\section{By J. D. Henshall, The Campden Food Preservation Research Association, Chipping Campden, Glos. GL55 $6 L D$}

Fresh foods can be described as highly perishable commodities. Of these, horticultural products are the most perishable, rapidly deteriorating after maturity or harvest. 'To ensure good retention of 'quality' and nutritional value, proper handling and storage practices must be observed. At $25^{\circ}$, the useful life of fruits and vegetables without some form of processing is short, e.g. fruits last from $I$ to $20 \mathrm{~d}$, leafy vegetables $\mathrm{I}-7 \mathrm{~d}$, and roots $7-5 \circ \mathrm{d}$.

Man competes for his nutrition. We must control micro-organisms, chemical reactions especially enzyme reactions, and also the depredations of pests-should we fail on two or more of these, we would rapidly starve. It is reported that more than $60 \%$ of the food products produced in under-developed countries are affected by some form of spoilage and are not used for human consumption.

The processing of food occurred long before any nutritional studies; perhaps it is just as well, because if Appert had known about nutrition and the effects of heating foods for a protracted period, he might have abandoned his approach to solving the problem of food preservation. In fact, it was almost 90 years after Appert's work (see Goldblith, Joslyn \& Nickerson, r96r) that any systematic studies were pursued involving the nutritional value of processed foods.

It is now common knowledge that nutrients are sensitive in varying degrees to $\mathrm{pH}$, oxygen, light, heat and trace metals.

Table 1. Relative stability of nutrients (from Harris \& von Loesecke, I960)

\begin{tabular}{lcccccc}
\multicolumn{1}{c}{ Nutrient } & Acid & Neutral & Alkaline & $\mathrm{O}_{2}$ & Light & Heat \\
Vitamin A & $\mathrm{U}$ & $\mathrm{S}$ & $\mathrm{S}$ & $\mathrm{U}$ & $\mathrm{U}$ & $\mathrm{U}$ \\
Vitamin C & $\mathrm{S}$ & $\mathrm{U}$ & $\mathrm{U}$ & $\mathrm{U}$ & $\mathrm{U}$ & $\mathrm{U}$ \\
Carotenes (pro-vitamin A) & $\mathrm{U}$ & $\mathrm{S}$ & $\mathrm{S}$ & $\mathrm{U}$ & $\mathrm{U}$ & $\mathbf{U}$ \\
Thiamin & $\mathrm{S}$ & $\mathrm{U}$ & $\mathrm{U}$ & $\mathrm{U}$ & $\mathrm{U}$ & $\mathrm{U}$ \\
Riboflavin & $\mathrm{S}$ & $\mathrm{S}$ & $\mathrm{U}$ & $\mathrm{U}$ & $\mathrm{U}$ & $\mathrm{U}$ \\
Essential fatty acids & $\mathrm{S}$ & $\mathrm{S}$ & $\mathrm{U}$ & $\mathrm{U}$ & $\mathrm{U}$ & $\mathrm{S}$ \\
Essential amino acids & $\mathrm{S}$ & $\mathrm{S}$ & $\mathrm{S}$ & $\mathrm{S}$ & $\mathrm{S}$ & $\mathbf{S} / \mathrm{U}$ \\
Minerals & $\mathrm{S}$ & $\mathrm{S}$ & $\mathrm{S}$ & $\mathrm{S}$ & $\mathrm{S}$ & $\mathbf{S}$
\end{tabular}

$\mathrm{S}$, stable (no important destruction); U, unstable (significant destruction).

Vitamin losses in particular can reach $75 \%$; however, in modern processes, losses rarely exceed $25 \%$ (Potter, I968). Ascorbic acid retention has been used as an indicator for all nutrient retention (Tressler \& Evers, I957) owing to the belief that, $32(1) 2$ 
if the vitamins survive the process, then all other nutrients are unaffected. Processing conditions which favour nutrient retention generally avoid extremes of the previously mentioned conditions, except perhaps with regard to heat; e.g. prolonged heating of orange juice in an open pan can destroy $100 \%$ of the ascorbic acid, but a properly produced frozen concentrate will retain $92-97 \%$ of the original content. It is fortunate that the techniques of fruit and vegetable preservation have evolved to produce endproducts as near fresh-like as possible, and in achieving this, many of the nutrients have been retained.

I was requested, for the purpose of this lecture, to review findings which have been made during the last ro years, i.e. after 1962 . This unfortunately meant that I could not consider the comprehensive work of Harris \& von Loesecke (I960) and like Cain ( 1967 ), who attempted to review the effects of processing on water-soluble vitamins, I found that recent work was, by and large, not very plentiful. This is in sharp contrast to the years between 1923 and 1960 when there were several established groups, e.g. Eddy and Kohman at the National Canners Association, and Tressler and Cameron's groups. In 1938, work on losses during canning was carried out at Chipping Campden. This work is described in a paper by Adam (1946), which was reissued in 1966 . This represented almost the sole work carried out on a realistic basis in this country.

There is quite a lot of information in the literature on the nutritive values of processed vegetables and allied products, but much of it is fragmentary and from an industrial point of view of questionable significance, because very little of the work has been done in collaboration with industry, or it has been done by workers who are only concerned with analysing foods for nutrient content and whose methods can now be questioned. I say this because, at the Institute of Food Science and Technology Symposium at Cambridge in October 1971, several speakers proposed newer methods for the examination of protein, carbohydrate, fat and vitamins.

In view of what I have just said, I think that it is useful to review the major stages in fruit and vegetable processing and examine the various critical steps which have been shown to influence the final nutrient content of a processed plant product. One of the most important steps in producing a product having certain desired characteristics is the correct choice of cultivar. It was shown by Guerrant, Vavick, Fardig, Dutcher \& Stern, (1946) that, of the factors they studied, the cultivar was one of the major ones affecting vitamin retention in tinned foods. In I97r, Somers, Farrow \& Reed (1971) at the National Canners Association showed that some nutritive factors are not associated with quality and others have a positive or negative correlationship. Therefore, in the development of new cultivars, the plant breeder must be aware of this possibility. There is some evidence that the US Food and Drug Administration will establish regulations that will prevent the release of new cultivars which will significantly lower the average nutritive value of a processed food.

Concerning the effect of cultural practices and what may be described as environmental conditions, it was shown before 1954 that, while the genetic make-up of a plant affects its nutrient composition, the prevailing light, temperature and 
available moisture can affect it, fertilizer practices may alter the composition slightly, the total effect of environment and cultivation is one of total amount or yield of nutrient per unit area.

We now come to a large gap in our knowledge of the total effects of processing. I refer to the unit process of harvesting. In the last 10 years, there have been many changes in harvesting practice and I have tried to find some evidence of published work on nutrient retention. Apart from total wastage figures given in Table 2 which have been collated at Campden over a period of years, there is no recent information on, for example, the effects of bruising.

\section{Table 2. Wastage values for fruit and vegetables for canning}

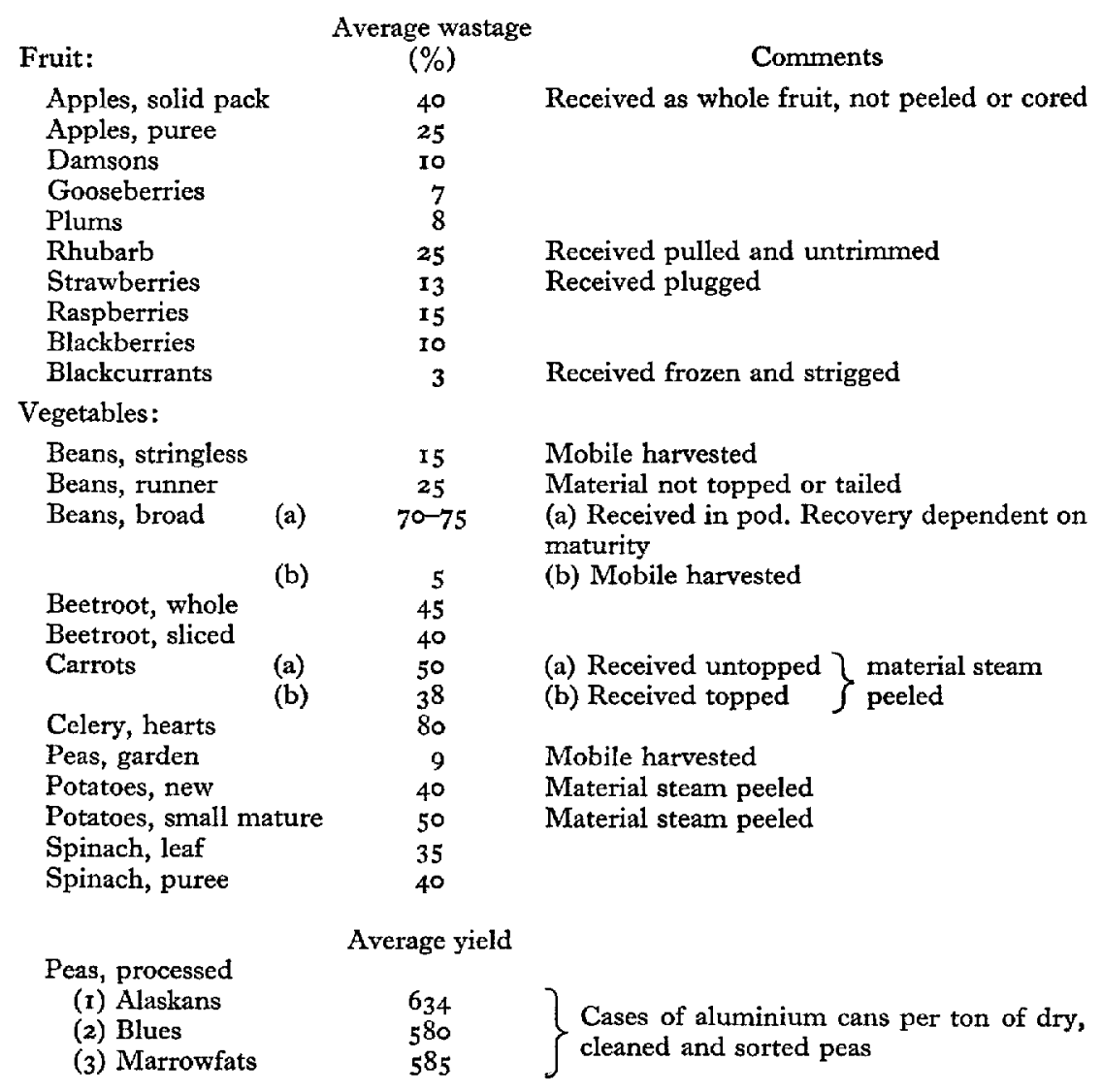

In the summer months a large variety of fruits and vegetables must be processed in a relatively short time and this leads to complications in organizing, e.g., a cannery. At relatively short notice, lines must be changed and this can sometimes lead to hold-ups in the process. There is an inevitable delay between harvesting and processing, because the crop must be transported from the field to the factory, and so these stages must be carefully managed. There is an abundant literature on 
this subject, almost purely concerned with quality aspects, but past studies on nutritive values have been largely concerned with ascorbic acid. It is often said that nutrient losses occur in these delays, but I have yet to find definitive statements as to the degree of loss or destruction with modern harvesting practices.

Up to the present, we have dealt with pre-processing conditions; now we come to processing effects.

The second unit process in fruit and vegetable technology is always washing. Here again, there is little in the literature which quantifies this step having regard to nutritive values. However, it is worthwhile mentioning the conditions which pertain to this process. In general, the water is recycled to a greater or lesser degree and detergents, wetting agents or antifoaming agents may be used. In this instance, we should know something about the effect on water-soluble vitamins and also the leaching of trace metals.

Following a wash, blanching takes place, and undoubtedly there is more information on this aspect than on any other. It is well documented, but I would refer you to the latest contribution by Varoquaux ( $197 \mathrm{I}$ ), where different varieties of petit pois, size-graded 'medium' to 'extra small', were examined after blanching for sugar losses, peroxidase activity, soluble nitrogen, ascorbic acid, calcium and potassium contents. The results showed that sugar loss increased with blanching time and was greater with the extra-small peas than with medium peas, e.g. for blanching for $90 \mathrm{~s}$ sugar losses were 10.6 and $37.5 \%$ respectively. Peroxidase destruction followed a similar pattern, occurring more quickly in water at $100^{\circ}$ than at $80^{\circ}$. At $100^{\circ}$, the activity in medium peas was destroyed in $60 \mathrm{~s}$ and at $80^{\circ}$ the time was I $5 \mathrm{~min}$. Losses of soluble nitrogen varied between $3^{8}$ and $42 \%$. Ascorbic acid retention was $97 \%$ after $60 \mathrm{~s}$, and $88 \%$ after $4 \mathrm{~min}: 2 \%$ calcium and $19 \%$ potassium were lost after $4 \mathrm{~min}$. The easiest way of summarizing knowledge here is to say that the effect on nutrient retention is product-dependent, that high-temperature-short-time (HTST) processes are usually desirable and a careful control of the product:water ratio is necessary.

Peeling processes for root vegetables can affect the nutrient content. Holman (1956) found that ascorbic acid concentrations were higher in the peel of apples than in the cortex, and nicotinic acid was higher in concentration in the peelings than in the peeled carrot root. Ascorbic acid is found in greater concentration just under the epidermis of the tomato than in the centre of the fruit. 'New' peeling techniques such as lye peeling, infrared peeling, steam peeling, have yet to be examined, but there is obviously a case for doing so.

Fruit and vegetable juices are beginning to have a bigger share of the processed fruit and vegetable market. There are many excellent products and, as the continental type of breakfast becomes more widespread, these items will become more significant with regard to their contribution to the dietary ascorbic acid, but here again, there is no published information on the effect of extracting and preheating juices. All one can say is that quick and efficient handling will minimize nutrient losses. Speedy inactivation of enzymes by heat will also minimize losses, but overheating can offset this benefit. 
We now come to a dividing point. Up to now, many unit processes are similar for all types of preservation. We must now briefly discuss the various methods of processing, and these are thermal, freezing and dehydration. Of these three, the greater losses occur in thermal processing. Heat, which is necessary to destroy micro-organisms, will also destroy some of the heat-labile nutrients; however, in recent years a great deal of research effort has been put into thermal processes which involve agitation, HTST and aseptic techniques. There is no doubt that vitamin retention has been greatly increased, but the aim of these processes has always been to improve organoleptic quality. Even here there are drawbacks, because we know of several instances where this has been done, but the products were rejected by buyers on the grounds that they were not what people were used to. For every $8^{\circ}$ increase in temperature, bacterial destruction is increased tenfold, and the rate of nutrient loss is only doubled. Luh, Antonakas \& Daoud (1969) have shown this very effectively with tinned carrots: those heated in conventional retorts had onethird the thiamin value of those tinned aseptically. Other methods under investigation such as reverse osmosis concentration, foam mat and vacuum drying, and cryogenic freezing, also give greater vitamin retention (Kaufman, Wong, Taylor \& Talburt, 1955; Lowe, Durkee \& Morgan, I968; Farkas \& Lazar, r969; Foda, Hamed \& Abd-Allah, I970).

Work before I 962 had shown the effects of packaging and storage temperature on nutrient retention. Generally, losses of ascorbic acid and some vitamins increase with packages that contain or allow permeability of oxygen, high storage temperatures and lengthened storage times. It is essential that the lowest practicable storage temperature $\left(-18^{\circ}\right.$ for frozen foods and $15^{\circ}$ for tinned and dehydrated foods) are used, and also that distribution is speedy and efficient. Here again, we are fortunate in that optimum storage conditions for the retention of organoleptic quality would appear to be those for optimum nutrient retention.

I have dealt so far with the detrimental effects of processing. We must not forget that processing can also have beneficial effects. From early work by agricultural chemists, it was realized that certain plants which were used for food, and in some instances were a staple item in the diet, had a deleterious effect on the growth of animals, and sometimes even caused death. It is worth summarizing these factors; for detailed accounts there have been several excellent works published recently (US National Research Council, 1966; Gontzea \& Sutzescu, 1968; Liener, I969; Bell, 1972). The important toxicants are as follows: enzyme inhibitors, e.g. proteolytic enzyme inhibitors are found in beans, peas, groundnuts, turnips, beetroot and potatoes; red kidney and wax beans contain haemagglutinins; goitrogens are found in members of the Brassica family; cyanogenetic glucosides occur in cassava, sweet potatoes, peas and beans; a diet of chick peas can cause lathyrism, and if you eat uncooked broad beans, you may suffer from favism. Many people are allergic to various plant foods, but they, not the plants, are generally abnormal.

It is most fortunate that cooking, possibly in conjunction with a soaking process, can get rid of some of these effects, either by extracting the active principles or by destroying them. It is therefore obvious that nutritive values are enhanced by 
processing. One example is famous, the work of Honavar, Shih \& Liener (I962) (Table 3).

Table 3. Effect of food processing on growth of rats (from Honavar et al. 1962)

Gain or loss in wt (g/rat per d)

$\begin{array}{lccc}\quad \text { Food } & \text { Raw } & \text { Autoclaved } & \begin{array}{c}\text { Soaked and } \\ \text { autoclaved }\end{array} \\ \text { Kidney bean } & -\mathrm{r} \cdot 04 & -0.4 \mathrm{I} & +\mathbf{r} \cdot 4^{8} \\ \text { Casein } & +\mathrm{r} \cdot 57 & & \end{array}$

The presence of these factors in the plants which we select (and I use the word advisedly) is extremely important in the role of the food technologist. One could make a case for this being the sole reason for processing certain plants, and then it would be necessary to characterize the exact process for eliminating these factors while retaining the maximum nutrient content. The opposite is also true, i.e. to show that toxic factors are not concentrated in the food, or added to it, during processing. This latter point is of especial importance-consider nitrosamines or the effect of solvent extraction on certain plant proteins or the possibilities of, e.g., freons acting as synergists in acute toxicity of pesticides (Anonymous, 1967).

To conclude, it is clear that, as more fruits and vegetables are processed, we must work to cut the losses of nutrients. After all, it does seem a little senseless that we should get rid of natural ascorbic acid which we have in effect purchased with potatoes or tomatoes and then pay to put it back again.

\section{REFERENCES}

Adam, W. B. (1946). In The Nation's Food [A. L. Bacharach and T. Rendle, editors]. London: Society of Chemical Industry.

Anonymous (1967). Inf. Bull. B.I.B.R.A. no. 6, p. 464.

Bell, E. A. (1972). In Phytochemical Ecology [J. B. Harborne, editor]. London: Academic Press.

Cain, R. F. (1967). Fd Technol., Champaign 21, 998.

Farkas, D. F. \& Lazar, M. E. (1969). Fd Technol., Champaign 23, 688.

Foda, Y. H., Hamed, M. G. E. \& Abd-Allah, M. A. (1970). Fd Technol, Champaign $24,1392$.

Goldblith, S. A., Joslyn, M. A. \& Nickerson, J. T. R. (196r). Introduction to Thermal Processing of Foods Vol. r, Wesport, Conn. : Avi Publishing Co.

Gontzea, I. \& Sutzescu, P. (I968). Natural Antinutritive Substances in Foods. Basle, Switzerland: S. Kayer.

Guerrant, N. B., Vavick, M. G., Fardig, O. B., Dutcher, R. A. \& Stern, R. M. (1946). F. Nutr. $32,435$.

Harris, R. S. \& von Loesecke, H. (1960). Nutritional Evaluation of Food Processing. London: John Wiley \& Sons Inc.

Holman, W. I. M. (1956). Nutr. Abstr. Rev. 26, 277.

Honavar, P. M., Shih, C. V. \& Liener, I. E. (1962). F. Nutr. 77, 109.

Kaufman, V. F., Wong, F., Taylor, E. H. \& Talburt, W. F. (1955). Fd Technol., Champaign 9, 120.

Liener, I. E. (editor) (1969). Toxic Constituents of Plant Foodstuffs. London: Academic Press.

Lowe, E., Durkee, E. L. \& Morgan, A. I. (1968). Fd Technol., Champaign 22, 915.

Luh, B. S., Antonakas, J. \& Daoud, H. N. (1969). Fd Technol., Champaign 23, 103.

Potter, N. N. (1968). Food Science. Westport, Conn. : Avi Publishing Co.

Somers, I. I., Farrow, R. P. \& Reed, J. M. (197I). Proc. Am. Med. Symp., New Orleans.

Tressler, D. K. \& Evers, C. F. (1957). The Freezing Preservation of Foods Vol. I, Westport, Conn.: Avi Publishing Co.

US National Research Council (1966). Publs natn. Res. Coun., Wash. no. 1354.

Varoquaux, P. (197 I). C.r. hebd. Séanc. Acad. Agric. Fr. 57, no. I I, p. 949.

\section{Printed in Great Britain}

